\title{
Hand Digit 2 Phalanx
}

National Cancer Institute

\section{Source}

National Cancer Institute. Hand Digit 2 Phalanx. NCI Thesaurus. Code C52776.

A bone in the second finger from the radial side of the hand, next to the thumb 